\title{
La cámara Gesell como medio de prueba en el ordenamiento procesal peruano
}

\section{Carlos Alfredo Escobar Antezano}

Abogado por la Universidad Nacional Mayor de San Marcos.

Docente de la Academia de la Magistratura. Juez Superior Titular del Distrito Judicial de Lima.

SUMARIO:

I. Introducción.

II. Epistemología y pericia.

III. Verdad, proceso penal y prueba.

IV. Posibilidad de alcanzar la verdad a través del proceso.

V. La cámara Gesell.

VI. La normatividad de la cámara Gesell.

1. Análisis de la Sentencia de la Casación N²1-2019/Arequipa.

1.1. Antecedentes.

1.2. Diferencias entre prueba preconstituida y prueba anticipada.

1.3. Los distintos supuestos que alude la Corte Suprema en la Sentencia de la Casación N²1-2019/Arequipa.

2. Análisis de otros Acuerdos Plenarios - $N^{\circ}$ 01-2011 y 04-2015-.

VII. Exactitud del testimonio.

VIII. Importancia de los estándares de prueba.

IX. Conclusiones. 


\title{
RESUMEN:
}

La cámara Gesell es una pericia con tendencia a ser científica que debe ser practicada por psicólogos y asistente sociales. Tiene que actuarse ante el Juez penal. Su finalidad es recibir el testimonio de la víctima y determinar su daño psicológico. Los psicólogos deben construir, en base a su expertise, conocimientos de la verosimilitud, memoria y coherencia el relato de la víctima, que es debatido en el juicio oral. Se debe garantizar el derecho de defensa del imputado, permitiendo la intervención de un perito de parte en la ejecución de esta pericia. La declaración de la víctima debe ser por una sola vez con el fin de evitar la "revictimización" — victimización secundaria— en virtud del interés superior del niño.

Palabras clave: epistemología forense, cámara Gesell, pericia, víctima, delitos contra la libertad sexual, menores de edad, victimización secundaria.

\begin{abstract}
:
The Gesell chamber is a forensic examination with scientific tendency that has to be practiced by psychologists and social workers. It has to be presented before a criminal judge. Its purpose is to receive the victim's testimony and to determine their psychological damage. The psychologists must build upon their expertise, the victim's knowledge and the truthfulness, memory and coherence of the victim's story, which must be debated during the trial. The right to defense of the accused must be guaranteed, allowing for the intervention of an expert from the defense during the forensic examination. The victim's declaration must be taken only once, in order to avoid further suffering.

Keywords: forensic epistemology, Gesell chamber, forensic examination, victim, sexual crimes, minors, secondary victimization.
\end{abstract}

\section{INTRODUCCIÓN}

En algún momento de sosiego tuve la suerte de recrearme con un relato profundamente reflexivo: "Funes el memorioso", de Jorge Luis Borges -1944-1. En este magistral cuento, el autor argentino nos mostraba un joven absolutamente desprovisto de la facultad de olvidar, de abstraer, de pensar, de simplificar; éste no solo recordaba cada detalle, cada circunstancia, cada experiencia; sino que, siendo incapaz de distinguir el pasado del presente, era una víctima incesante del retorno de sus recuerdos que volvían a él, una y otra vez, con la intensidad de una vivencia actual.

Me resultó inevitable relacionar esta intrigante imagen con los diversos ítems de mi investigación; pues, si bien la constante revictimización sufrida por Funes era el producto del particular funcionamiento de su cerebro y, en cambio, la revictimización de los menores víctimas de abuso reside en que son inducidas por terceros a recordar el hecho traumático que vivieron, en ambos casos, se presenta una innecesaria reprogramación de recuerdos, en un caso, por la ausencia de la facultad de olvidar y, en el otro, por la ineficacia de nuestro sistema de justicia. En esa línea, uno de los derroteros que con más ahínco sigue mi investigación es que la entrevista de cámara Gesell sea practicada una sola vez, a efectos de que no "revictimice" a los menores de edad víctimas del delito de violación sexual.

Reconociendo que la dogmática del Derecho Procesal —el mecanismo que el estado impone para reconocer, reivindicar o distribuir derechos- aún se encuentra en construcción pues no ha tenido la atención dogmática de los juristas, estimo necesario en lo relativo a la cámara Gesell, construir una argumentación y directri-

1. Jorge Luis Borges relata su encuentro con Irineo Funes, un singular joven de 19 años con la extraña habilidad de cronometrar el tiempo sin necesidad de instrumento alguno. El uruguayo Funes tuvo un accidente que lo dejó postrado sin poder recuperarse más. Lo anecdótico es que después del accidente se potencian sus habilidades con la aparición de una memoria extraordinaria capaz de recordar lo infinito que obviamente terminará abrumándolo. En su soledad, aprende idiomas, crea sistemas de numeración, cataloga y clasifica todo lo que pueda caber en su mente, hasta morir a los 21 años de una congestión pulmonar. 
ces que considere a las ciencias que la integran, los profesionales y protocolos, desde una perspectiva epistemológica a fin de incrementar los rangos de fiabilidad.

El punto de partida o antecedente de la cámara Gesell es la declaración testimonial, que no ha tenido un tratamiento racional en nuestro medio, ni en ningún otro sistema procesal de la región. En ese orden de ideas, el caso peruano es peculiar porque frente al Congreso se erige el Tribunal de la Santa Inquisición, donde se encuentran instaladas mesas de tortura, salas de audiencia con crucifijos - con sogas encubiertas manejadas por el director del debate para que la imagen de Cristo mueva la cabeza en el momento decisorio-, y donde se practicaba la valoración del peso de un testigo en base a títulos nobiliarios o eclesiásticos. Estos rezagos de la Santa Inquisición no solo administraban hechos o eventos de fe, sino que tenían influencia en todo hecho que generaba trascendencia social y económica. Resalta en la justicia virreinal el juicio a un acaudalado hombre de la sociedad limeña Mateo Salado, de los valles de Maranga y Magdalena, a quien se le ajustició por el solo hecho de no adjurar a su condición de judío, al entenderse que dicha negativa representaba un atentado contra la fe católica.

En los años sucedáneos de la República, durante la vigencia del Código de Procedimientos Civiles — derogado en el año 1984-, resalta el juramento decisorio, que era una institución que, bajo el sometimiento a la fe religiosa, llevaba a aceptar una pretensión por más aberrante que fuere; se recibía la extremaunción -mecanismo por el cual el cura imponía los santos óleos - si no se aceptaba hechos que imponían como ciertos y ello de manera incuestionable podía llevarse a las Cortes, además de llevar adosado a tan magna gracia ceder propiedades a la iglesia o al confesor.
Hago mía la afirmación de Jordi Nieva Fenoll al referirse al tratamiento que hemos otorgado a la declaración testimonial "cargada de subjetivismo", que incrementa los errores judiciales; y que para el aporte objetivo del testimonio debe actuarse desde la psicología del testimonio. Señala también que el testimonio se encuentra enriquecido por otros campos científicos como la neurociencia que estudia los procesos cognitivos y de memoria, campo que solo refiero ya que mi objeto es la cámara Gesell como medio probatorio.

Si como afirma Jordi Ferrer Beltrán, el proceso penal sufre una implosión porque desde allí se pretende solucionar un gran número de conflictos, entonces la probanza de hechos tiene que observar principios y garantías constitucionales como la presunción de inocencia, el derecho a ser informado del hecho, el derecho de defensa y la imputación que da derecho a la prueba. En ellos tiene relevancia el objeto de prueba, destinatario de la prueba y los medios probatorios.

El esfuerzo de explicar la memoria humana fue anterior a los experimentos de Wundt en Leipzig. Así, Platón, el estagirita, planteó las asociaciones como un aspecto esencial en la reminiscencia en la actividad "mnémica" ${ }^{2}$ influyendo en el racionalismo y empirismo epistémico.

No solo la tradición filosófica problematizó y propuso planteamientos teóricos, sino que en el devenir epistémico sobre la mente, las escuelas psicológicas fueron el marco para el desarrollo de nuevos planteamientos teóricos como el cognitivismo y sus avances, ubicada dentro del llamado hexágono cognitivo ${ }^{3}$ y constituido por la interrelación de disciplinas como la neurociencia, la inteligencia artificial, la psicología, la lingüística, la antropología y la filosofía, pretende explicar los mecanismos básicos y profundos que dan origen al conocimiento.

2. En su reflexión sobre la memoria y la reminiscencia hay un acercamiento de Aristóteles a la neurociencia.

3. Howard Gardner, The Mind's New Science: A History of the Cognitive Revolution (New York: Basic Books, 1985). 
En este panorama histórico de posturas muy trascendentes en todos los campos del conocimiento surge en el ámbito del derecho los aportes del pensamiento alemán, del connotado "iusfilósofo" Robert Alexy, en la argumentación jurídica, la teoría de los derechos fundamentales y una teoría del derecho, basada en la ética del discurso.

Consciente de la importancia y trascendencia de este nuevo sistema de prueba, postuló que la entrevista única en esta cámara de un menor de edad, víctima de violencia sexual, es una pericia y no una declaración ante tercero con cualidades científicas, buscando evitar la revictimización del agraviado.

La declaración de la víctima debe ser única y para ello debe estructurarse en el marco de un protocolo riguroso, exhaustivo, suficiente y probabilístico, reuniendo los elementos que vinculen o aparten al imputado al hecho investigado. Es realista lo que afirma Jordi Ferrer Beltrán que no es posible alcanzar la certeza de un hecho que se reconstruye, lo que se logra son grados de probabilidad.

Mi experiencia judicial con este medio probatorio y su subsecuente investigación teórica me permiten advertir que, en el proceso de valoración individual o conjunta, la pericia en situaciones análogas muestra contenidos en esencia distinta y contradictoria. Es fundamental establecer la unidad del dictamen y no es posible sustituir este medio probatorio con otro que cumpla con el objetivo. Con el rigor de toda prueba científica, me he permitido recibir en juicios orales ratificaciones de pericias de peritos psicólogos realizados en las etapas de instrucción del viejo Código Procesal, aún vigente en Lima, y advertir que, con aires de suficiencia y sin ningún rubor, estos profesionales afirman que el peritado es autor de un determinado delito. Sin embargo, al examinar el contenido de tales pruebas, exámenes o tests, lamentablemente compruebo que los peritos no explicitan ni el sustento epistemológico que ampara sus conclusiones ni el criterio metodológico empleado a fin de arribar a las mismas; subrayando continuamente que su conclusión es el resultado de su experiencia cotidiana y de sus patrones de responsabilidad.

\section{EPISTEMOLOGÍA Y PERICIA}

Actualmente, el desarrollo de las comunicaciones nos da a conocer que en auditorios cada vez más amplios se presentan cuestionamientos a la lógica, ética y retórica; asimismo, se revisan, sin las conveniencias de grupos de poder político-económico o sin atisbo de subjetividad religiosa, las teorías iusnaturalistas y "iuspositivistas" del razonamiento judicial. Ello en base a que los estados contemporáneos se estructuran dividiendo poderes que distribuyen justicia y solucionan sus conflictos con base en un racionalismo práctico. En este contexto, los usuarios discuten sobre sus pretensiones en un marco de igualdad de condiciones y de la mano de un proceso dotado de un conjunto de garantías.

En este escenario, se consolida la teoría de la argumentación jurídica de la Escuela de Alicante liderada por Manuel Atienza Rodríguez - traductor de la Teoría de la Argumentación Jurídica de Robert Alexy-, quien predica, en cuanto foro lo convoquen, esta nueva visión del Derecho como si de un nuevo evangelio se tratara, el mismo que es recibido con beneplácito por una masa - afortunadamente - cada día más crítica y estudiosa.

A sus obras ya bien conocidas - Las razones del Derecho, 1991, Tras la justicia, 1993, Las piezas del Derecho, 1996, El sentido del Derecho, 2004- se suma ahora este importante trabajo en el cual Atienza plantea, siguiendo las grandes tradiciones anglosajonas, y también las innovaciones de la teoría jurídica continental, una concepción diferente del Derecho: considera que el Derecho es esencialmente una actividad argumentativa que tiene que ver con el lenguaje, con la lógica y con otras formas de argumentación, un tanto soslayadas en la cultura jurídica contemporánea, como la tópica, la retórica y la dialéctica; disciplinas todas que tienen su origen en el mundo antiguo y, sobre todo, en la obra de Aristóteles. 
Habiéndose producido un cambio de paradigmas generales con la tendencia de abordarlo desde la epistemología, aplicando el método científico de manera coherente se estudia el problema particular, se construyen herramientas que otorgan contenido a los significados de medios de prueba y pericias. La verosimilitud, veracidad, probabilidad y fiabilidad nos permitirán argumentar con lógica y coherencia.

Es importante citar "La prueba de los hechos" de Michele Taruffo, porque alude directamente a la prueba y los medios probatorios. Afirma que la determinación de los hechos depende del Derecho, porque se aplica la subsunción, existe un marco de hechos que en el caso penal es la acusación sometida al control de las partes, así se determinan hechos principales o relevantes que deben ser probados a través de los medios probatorios.

\section{VERDAD, PROCESO PENAL Y PRUEBA}

En el ámbito jurídico y filosófico existe un debate entre dos posturas extremas sobre la posibilidad de alcanzar la verdad: aquella que admite esa posibilidad y quienes niegan la posibilidad de la verdad alcanzable en el proceso judicial.

Entre quienes niegan la posibilidad de encontrar la verdad en el proceso, están los que, desde una perspectiva escéptica radical, niegan la posibilidad absoluta de alcanzar la verdad al no contar con ningún método, incluido el proceso judicial, que permita con certeza alcanzar algún conocimiento racional.

Con esta postura resaltan el escepticismo y el idealismo. El primero afirma que, aplicadas al campo jurídico, las apreciaciones judiciales, las decisiones y en general los actos procesales son representaciones subjetivas, pues las particularidades de los sujetos que participan en el proceso los hechos conllevan a la existencia de "varias" verdades. El segundo, también radical, sostiene que el conocimiento se compone sola- mente de construcciones mentales sin ninguna vinculación con la realidad empírica ${ }^{4}$.

En síntesis, hay quienes afirman que la verdad se ubica en la realidad empírica y es posible acceder a ella; y por el contrario, otros sostienen que se encuentra solo en la mente del sujeto cognoscente que construye las premisas sobre esa realidad. En términos procesales la discusión sería si la realidad existe en sí, por fuera del proceso y a la misma es posible conocerla a través de los medios probatorios, o solo existe en la mente del Juez.

Asimismo, existe la tesis lingüística según la cual la realidad que conocemos se nos transmite a través del lenguaje, esto es, para hacer comprensible esa transmisión se debe acudir al vehículo del lenguaje, puesto que no hay otro modo comprobado de transferencia del conocimiento. Pero para transmitir el lenguaje el portador de la idea ha debido hacer una comprensión de las particularidades de lo que se transmite, como también lo hará quien recibe la transmisión. Y al respecto se tiene que toda comprensión implica una interpretación. De suerte que los lenguajes que se transmiten van siendo enriquecidos por la interpretación de los que intervienen.

Así, se tiene que si toda comprensión es interpretación, no queda otra alternativa que concluir que en el proceso judicial las formas a través de las cuales se transmiten las ideas de lo acontecido en la realidad empírica llevan necesariamente la impronta del transmisor, por lo cual será imposible lograr una verdad completamente objetiva. Incluso radicalizando estas ideas podría admitirse que ni la verdad del proceso ni ninguna verdad existe como tal, en la medida en que lo que se recibe en cualquier escenario de comunicación a través del lenguaje - prueba judicial - son interpretaciones de la verdad gracias a las comprensiones previas que se han debido efectuar por quienes pretenden comunicar las ideas ${ }^{5}$. Piénsese

\footnotetext{
4. Taruffo.
} 
que este análisis no es extraño en la legislación: por ejemplo, el nuevo Código de Procedimientos Penales restringe en grado sumo las pruebas, especialmente los testimonios, en la medida en que se entiende que mientras más larga sea la cadena de personas que transmiten el lenguaje habrá un mayor número de comprensiones e interpretaciones acerca de la realidad empírica.

Otras posturas no guardan relación exclusiva con el asunto epistemológico del proceso, sino más bien con la concepción ideológica o política que se tenga sobre él. Estas ideas apuntan a explicar que el proceso judicial no es un medio para alcanzar la verdad, sino que su fin primordial es el de solucionar conflictos, por lo que tal búsqueda es extraña y por lo tanto es innecesaria frente al proceso e incluso puede llegar a ser contraproducente, en la medida en que la composición del litigio implica dejar satisfechas a las partes con independencia de cuál hubiese sido con exactitud la base fáctica. Desarrollos adicionales de estas mismas ideas se encausan a establecer que el proceso judicial no se encuentra diseñado para alcanzar la verdad, esto es, que desde el punto de vista epistemológico, el proceso contiene serias deficiencias de metodología, pues su fin, se insiste, es la resolución de las controversias puestas a disposición del Juez ${ }^{6}$.

\section{POSIBILIDAD DE ALCANZAR LA VERDAD A TRAVÉS DEL PROCESO}

Tanto el realismo crítico y radical como la teoría de la correspondencia postulan la realidad empírica aprehensible para su observador, en consecuencia, las proposiciones sobre esa realidad concuerdan con ella, siendo estas necesariamente verdaderas. De igual forma, el relativismo guarda relación con las teorías semánticas afirmando que la realidad se ve de varias formas. Esto quiere decir que sobre la realidad puede haber varias "verdades" sin que sea correcto descalificar a priori ninguna de ellas e incluso todas ellas pueden eventualmente ser verdaderas. No obstante, esta circunstancia no impide que sea posible encontrar la versión de los hechos que más se acerque a la experiencia.

Existen, además, posturas que conciben al proceso como un medio para alcanzar la verdad. Consideran que, para alcanzar una decisión justa, el Juez debe decidir partiendo de los hechos ocurridos. Así, la sentencia deberá reproducir los hechos del caso, la abstracción contenida en las normas jurídicas, específicamente en su consecuencia jurídica. De ese modo la adecuación de los hechos aducida en el proceso implicará una decisión justa.

Toda decisión justa debe contener una determinación veraz sobre lo acontecido. Si la base fáctica en la que se apoya el Juez no coincide con lo sucedido, la decisión simplemente solucionará una situación problemática no planteada cuyos efectos nocivos posteriores mantendrán el conflicto.

Finalmente, se encuentran algunas teorías que sostienen que la verdad sí se puede alcanzar en el proceso, por cuanto desde el punto de vista epistemológico éste no se diferencia en gran medida de otros métodos en los cuales se busca alcanzar conocimiento; ello a pesar de que ciertamente la regulación legal sobre la construcción de la base fáctica en el proceso, que no es otra que la reglamentación sobre el decreto, práctica y valoración de los medios de prueba y el debido proceso, crea una metodología sui generis para alcanzar el conocimiento y que ciertamente puede llevar a hablar de una especie de verdad judicial construida en el proceso que eventualmente difiere de otras verdades elaboradas con metodologías diferentes.

No es esta la vieja discusión acerca de la exis-

\footnotetext{
5. Gadamer.

6. Taruffo.
} 
tencia de una verdad "procesal" por oposición a una verdad "real" o "material". Es, más bien, la aceptación de la verdad conseguida en el proceso, el cual debe ser diferente de otras verdades desde el punto de vista epistemológico, dadas las particularidades del método judicial para alcanzar el conocimiento.
En el ámbito penal todo procedimiento penal llega a establecer una verdad legal que es concebida de modo distinto según el modelo procesal que se trate. Así, Luigi Ferrajoli distingue entre dos modelos procesales: el decisionista y el garantista, si bien los dos buscan una verdad, esta es diferente en cada uno.

Tabla 1. Criterios de verdad de los modelos procesales.

\section{Criterios de verdad de los modelos procesales}

Modelo procesal decisionista — sustancialista-

Verdad máxima: sustancial y global fundada sobre valoraciones.

Verdad política obtenida sin límites normativos.

Carácter valorativo de las hipótesis acusatorias que reclaman, más que pruebas, juicios de valor no refutables por la defensa -apriorísticamente intuida por el juzgador-.
Modelo procesal garantista - cognoscitivo-

Verdad mínima: aproximativa o relativa.

Verdad procesal empíricamente controlable y controlada.

Averiguación de la verdad mínima, garantizada por el carácter empírico y determinación de las hipótesis acusatorias bajo cánones de conocimiento: presunción de inocencia, carga de la prueba, in dubio pro reo, publicidad del procedimiento probatorio, principio de contradicción y derecho de defensa mediante la refutación de la acusación.

El fin —fundado y garantizado por los vínculos señalados- está legitimado por los medios.

7. Elaboración en base a la información de: Luigi Ferrajoli, Derecho y razón. Teoría del garantismo penal (Madrid: Trotta, 2004) y Epistemología jurídica y garantismo (México: Fontamara, 2004). 
El cuadro muestra que la verdad empíricamente controlada - comprobada, verificada, contrastada - guarda relación con las garantías procesales que se exigen en el procedimiento acusatorio como modelo cognoscitivo, mientras que la verdad controlable - que se puede controlar - se refiere a la actividad de las partes para la formación y producción de la prueba, a los límites normativos y a la actividad que se exige a las partes procesales porque el caso judicial les pertenece.

En sintonía con lo anterior, la verdad que se pretende obtener en un procedimiento acusatorio está previamente controlada porque existen imperativos normativos que tienen que ver con la obtención, aseguramiento o recolección de cualquier objeto, instrumento, huella, indicio, persona, etc., que lleve al esclarecimiento de los hechos penalmente relevantes.

También debe hacerse referencia a una cierta verdad negociada, que dota de eficiencia a los sistemas de justicia, simplificando el trabajo del Juez, al permitir que las partes consensuen el thema probandum.

\section{LA CÁMARA GESELL}

Se concibe la cámara Gesell como dos ambientes separados por un vidrio del que solo se observa de un lado. Uno de ellos está dotado de sistemas de grabación de audio y video, y el otro es de observación. El primer ambiente debe estar debidamente acondicionado para menores: debe estar pintado con colores vivos, contener dibujos y eventualmente muñecos. Por norma transversal deben funcionar en cada sede de corte de justicia. Son de manejo del Poder Judicial, al que accede el Ministerio Público en su actividad, porque también cuenta con 80 cámaras en los distritos judiciales de los cuales están implementadas.
Arrom Loscos define la cámara Gesell como un sistema de video de conferencia que permita la comunicación bidireccional y simultánea de la imagen y el sonido y la interacción visual, auditiva y verbal entre personas, asegurando la posibilidad de contradicción de las partes y el respeto a los derechos de defensa.

Actualmente por mandato legal solo se actúa ante el Juez de investigación preparatoria, en razón que en cada distrito judicial hay en funciones un Juez de turno todos los días del año al que se explica los procedimientos empleados. Está prohibido emplear tests pero debe adosarse a la pericia los mecanismos y pruebas que han empleado en la pericia. La razón es que la pericia tiene que ser suficiente en forma y fondo y que la ampliación se realiza de manera excepcional para aclarar ${ }^{8}$.

La cámara Gesell es un sistema de intervención de profesionales que desde sus perspectivas abordan la conducta para obtener la declaración de la víctima infantil. En condiciones de daño en la conducta — no siempre- en las que está vetado practicar tests pero sí se pueden utilizar técnicas de interrogatorios para develar un evento aflictivo de una víctima infantil en condiciones de recurrencia social ${ }^{9}$, debe administrarse solo por única vez.

La victima debe construir un relato a partir de hechos vivenciados, lo que hace necesario recordar determinadas circunstancias. Algunos detalles de los sucesos acontecidos merecen una consideración especial desde el punto de vista tanto de su procesamiento perceptivo como de su posterior recuerdo. Manzanero y Álvarez sugieren considerar la diferencia entre detalles centrales y periféricos, siendo los detalles centrales aquellos a los que el testigo evocará con más atención y que recordará mucho mejor, aunque dicha centralidad dependerá de

8. Sentencia de Casación N²1-2019/Arequipa de la Sala Penal Permanente de la Corte Suprema de Justicia de la República.

9. Según el Instituto de Medicina Legal del Perú, entre enero y junio, hubo un total de 3,400 atenciones en cámara Gesell por delitos contra la libertad sexual a niños, niñas y adolescentes. 
cada testigo y no sólo del tipo de detalle concreto de que se trate. ${ }^{10}$

La Convención Internacional de los Derechos del Niño impone a los estados que ratificamos la obligación de aplicar las normas en el territorio, incurriendo en responsabilidad internacional de acuerdo al trato que cada estado le da a los niños. Como aspectos principales de esta norma, son incluidos en el derecho interno del estado suscriptor los niños y adolescentes como sujetos de derecho, otorgándoles una protección integral.

¿Por qué razón la cámara Gesell no evita la revictimización del agraviado?

Estadísticamente, por un hecho de connotación sexual a la víctima, se le pregunta mínimamente alrededor de 15 veces: cuando se da a conocer el hecho; si se denuncia en el colegio, en la Comisaría, en la Fiscalía de turno de delitos, en la Fiscalía de familia, en el Ministerio de la Mujer, en la Defensoría del Niño, en Medicina Legal, en la Secretaría del área de Psicología y en la cámara Gesell. Además, el Fiscal en la investigación preparatoria, en la ampliación, en la audiencia privada de juicio oral y eventualmente en la casación - concebido en las actuales circunstancias de manera oficial y natural de permisividad y justificación del operador de justicia-. La Cámara Gesell es solo un "proceso formalista y protocolar", partiendo del concepto legal, es una pericia en base a un testimonio practicado por un profesional en la conducta quien emite un dictamen que es sometido al Juez para su valoración.

¿Por qué razón tiene que ser un extraneus psicólogo cognitivista- el que reciba la declaración de la víctima en la cámara Gesell?

Porque el testimonio como medio de prueba comprende dos elementos: la persona y el testimonio. Nos referimos a quiénes son los actores, la observación del protocolo de la pericia, la cautela del derecho de defensa, la oportunidad de practicarlo. El aporte de las ciencias y métodos científicos de aproximación a la credibilidad y fiabilidad causa que permanentemente revisen los conceptos del testimonio, desde varias vertientes como la neurociencia, la psicológica del testimonio. En ellas destacan la memoria el relato, el mito en relación directa con la edad, sexo, instrucción de la víctima, rasgos y vinculación con la víctima.

Es contributivo el desarrollo de la neurociencia — solo haremos la referencia - porque recién a fines de siglo se comenzó a estudiar el cerebro, el proceso de percepción, memoria y relato en personas vivas. Anteriormente solo se hacía en cadáveres e incluso tiene carácter anecdótico que se conserve los cerebros de grandes criminales o genios de ciencia y artes para descubrir nuevas cualidades, pero actualmente, utilizando formas mensurables, es materia de estudio el hipotálamo en razón que es la zona donde se almacena los hechos percibidos.

Solo indicamos que la psicología científica denomina memoria al conjunto complejo de sistemas o estructuras relacionadas, cuyo sustrato neurológico está más o menos identificado, y cuyos parámetros de funcionamiento - tipo, cantidad de información que manejan y tiempo que mantienen la información - suelen estar medidos. La información que entra del exterior a través de los sentidos y la información que almacenamos de manera estable en nuestra memoria fluye entre estos sistemas y se desarrolla toda una variedad de procesos que generalmente son de tres tipos: codificación, almacenamiento y recuperación de información.

\section{LA NORMATIVIDAD DE LA CÁMARA GE- SELL}

Considero oportuno evaluar la normatividad que regula la cámara Gesell. Hay que reconocer que plantear transversalmente su tratamiento es novedoso. Considero que las Juezas de la 
Corte Suprema se han nutrido de la corriente filosófica de Nancy Fraser, quien en los años 1990 en Estados Unidos - a consecuencia de la perestroika de los estados soviéticos-inicia una corriente en busca del valor justicia. Desde el punto de vista cultural, se reconoce diversos grupos respecto de los cuales existía una diferencia de trato: las mujeres, los niños, los grupos étnicos minoritarios y homosexuales. Estos grupos son objeto de violencia, por lo tanto, es necesario reconocerlos a fin de el valor justicia se redistribuya y se logre una solución equitativa en la que solo se privilegie la condición humana.

Lo anterior, pues, se ha materializado en un gran esfuerzo multisectorial al interior del Estado centralista, por lo que se promulga una ley para la defensa de mujeres, niños y de personas en incapacidad en situaciones de agresión, la Ley 30920 del 7 de marzo de 2019, que declara de interés público y prioridad nacional la implementación progresiva de cámaras Gesell en Fiscalía y Juzgados de Familia. Este es el mejor intento de orden práctico y dogmático, pues ha articulado otras reparticiones del Estado para implementar políticas públicas.

En la misma línea, el Poder Judicial ha emitido la Resolución Administrativa 277-2019/CE-PJ del 3 de julio de 2019 que propone un protocolo de entrevistas únicas para niños y adolescentes en la cámara Gesell en procesos judiciales. Establece pautas para evitar la revictimización y procedimientos de operatividad; asimismo, rescata, como pocos documentos legislativos, que se trata de un plan quinquenal y el acatamiento a las cien reglas de Basilea. Se nota el apoyo continuo de la Asociación Solidaridad Países Emergentes - ASPEN-, órgano que trabajó el protocolo de la entrevista única en cámara Gesell.

Lo novedoso de estas directrices es que contiene: las definiciones de cámara Gesell para la entrevista de menores y adolescentes; que deben ser grabadas en audio y video; que es una diligencia judicial excepcional en la que se aplica el principio de inmediación; reitera que es por única vez para evitar la revictimización del ofendido y que puede practicarse de oficio o de parte ante la presunción de un abuso sexual - para tal efecto debe observarse el consentimiento informado, que consiste en darle a conocer a la víctima o a la persona que lo tiene a cargo el fin de esta entrevista-. Aquí, como tantas veces, estimo que la interpretación del operador de justicia no requiere aclaración porque se trata de un proceso rápido formal que se hace ante el Juez.

\section{Análisis de la Sentencia de Casación No 21-2019/Arequipa.}

\subsection{Antecedentes.}

La Segunda Fiscalía Provincial Corporativa de Arequipa solicitó el 19 de julio del 2018 que se actúe como prueba anticipada las declaraciones de las menores N.S.C. y A.S.C., pese a que éstas ya habían declarado en cámara Gesell el 14 de mayo del 2018.

El Cuarto Juzgado de Investigación Preparatoria de Arequipa mediante auto de fecha 3 de octubre del 2018 dispuso la realización de tal audiencia única.

La Segunda Sala de Apelaciones de Arequipa mediante auto del 31 de octubre del 2018 confirmó el auto de primera instancia. Contra el referido auto, la defensa interpuso recurso de casación.

El sustento del recurso de casación es que el segundo artículo de la Ley 30364 - del 23 de noviembre del 2015 - restringe la declaración de menores víctimas de abuso sexual a la etapa de juicio oral; esto es, no cabe una segunda declaración de los menores en sede de investigación preparatoria e intermedia. El artículo 18 de la Ley 30364 —reformada por Ley 30862 del 25 de octubre del 2018- señala que se debe evitarse la doble revictimización de las personas agraviadas a través de declaraciones reiterativas o de contenido humillante. El artículo 19 de la referida Ley señala que la declaración debe practicarse bajo la técnica de entrevista única y tiene la calidad de prueba preconstituida - lo que constituye, ciertamente, un yerro conceptual porque la prueba 
preconstituida está referida a la prueba material y a la documental, más no la prueba personal-; además, establece que el Juez sólo puede practicar una diligencia de declaración ampliatoria de la víctima, en los casos que requiere aclarar, complementar o precisar algún punto sobre su declaración.

Empero, el Decreto Legislativo 1386 del 4 de septiembre del 2018 señaló que tal declaración se tramita como prueba anticipada. Además, se añadió al numeral 1 del artículo 242 del nuevo Código Procesal Penal que regula la prueba anticipada el literal d), que permite recibir a través de la prueba la declaración de niños y adolescentes víctimas de abuso sexual. Además, el Decreto Legislativo 1307 estableció que la prueba anticipada también puede pedirse en la etapa de diligencias preliminares.

\subsection{Diferencias entre prueba preconstituida y prueba anticipada.}

La "prueba preconstituida" es un complejo compuesto por aquellos actos de investigación de carácter material —no personal-, objetivos e irreproducibles, que se practican con anterioridad al juicio oral por la Policía Nacional del Perú o el Fiscal ${ }^{11}$. En el juicio oral únicamente cabe su ratificación formal, cuando sea necesario llamar a los autores para impugnar el modo en que se han realizado o su reproducción - por ejemplo, se solicita la presencia de los policías que realizaron una inspección ocular a efectos de impugnar el procedimiento seguido- ${ }^{12}$. El informe policial contiene elementos de prueba preconstituida - por ejemplo, actas de constancia, pericias, recogida y conservación del cuerpo del delito, levantamiento del cadáver, etc.-.

La prueba anticipada es un acto de investigación de carácter personal, de carácter irrepetible y urgente, que se lleva a cabo por el Juez de la investigación preparatoria, bajo las pautas de ejecución del juicio oral —oralidad, inmediación y contradicción-13. A diferencia de la prueba preconstituida, su objeto no es documental, sino testifical y pericial. En tanto lo característico de la prueba anticipada es que es una prueba típica del juicio oral que se ciñe a la prueba personal -testimoniales, examen pericial, careos- Sin embargo, el artículo 242.1c del Nuevo Código Procesal Penal ha incluido tres diligencias que, propiamente, son pruebas materiales - reconocimiento, inspección judicial y reconstrucción-.

\subsection{Los distintos supuestos a que alude la Corte Suprema en la Sentencia de Casa- ción $\mathrm{N}^{\circ}$ 21-2019/Arequipa.}

A fin de entender con mayor claridad los distintos argumentos presentes en la Sentencia de Casación N²1-2019/Arequipa, resulta muy útil distinguir tres supuestos:

a) Los casos en donde, al amparo de la ley procesal vigente en tal momento - la Ley 30364 del 23 de noviembre del 2015-, la declaración de la presunta víctima - vía cámara Gesell- se realizó sólo bajo la dirección del Fiscal - como prueba preconstituida - y su ejecución fue correcta pues estuvo a cargo de un experto y siguió los protocolos consolidados - y respetó el principio de contradicción - presencia de la defensa técnica de las partes procesales e intervención en la formulación de preguntas, repreguntas y objeciones-. Aún cabe diferenciar estos casos según:

(i) Si la declaración de la presunta víctima tuvo algún "defecto interno relevante" que hiciese necesaria una aclaración, complementación o precisión.

(ii) Si la declaración de la presunta víctima no tuvo ningún "defecto interno rele-

11. César San Martín Castro, Derecho Procesal Penal. Lecciones (Lima: INPECCP, 2015), 579.

12. Ibíd.

13. Ibíd. 
vante" que amerite una aclaración, complementación o precisión.

b) Los casos en donde, al amparo de la ley procesal vigente en tal momento - la Ley 30364 del 23 de noviembre del 2015-, la declaración de la víctima - vía cámara Gesell- se realizó sólo bajo la dirección del Fiscal - como prueba preconstituida- $y, 0$ bien tuvo defectos en su ejecución, o bien no respetó el principio de contradicción.

c) Los supuestos en donde, al amparo de la ley procesal actualmente vigente - el Decreto Legislativo 1386 del 4 de septiembre del 2018-, la declaración de la víctima vía cámara Gesell- se llevó a cabo bajo la dirección del Juez de la investigación preparatoria - como prueba anticipada- y su ejecución fue correcta y no irrespetó el principio de contradicción. Cabría, también, distinguir estos casos según:

(i) Si la declaración de la presunta víctima tuvo algún "defecto interno relevante" que hiciese necesaria una aclaración, complementación o precisión.

(ii) Si la declaración de la presunta víctima no tuvo ningún "defecto interno relevante" que amerite una aclaración, complementación o precisión.

Como veremos, la Sala Penal Permanente de la Corte Suprema en su Sentencia de Casación $N^{\circ}$ 21-2019/Arequipa alude a los distintos casos antes señalados. Por ello, el panorama antes delineado nos será de mucha utilidad para identificar a qué grupo de supuestos se refieren los distintos considerandos de la sentencia antes citada.

En primer término, la Corte Suprema refiere a los supuestos que hemos identificado como a) (ii) -esto es, los casos en donde la entrevista única, correctamente ejecutada y respetuosa del principio de contradicción, no hubo necesidad de aclaración, complementación o pre- cisión y fue dirigida por el Fiscal como prueba preconstituida-. El problema en lo relativo a estos supuestos reside en que convergen dos interpretaciones antagónicas tanto respecto a la eficacia probatoria de la precedente entrevista única - prueba preconstituida - como en lo referente al alcance de la nueva regulación de la entrevista única como prueba anticipada.

En efecto, una primera interpretación afirma que la primigenia declaración de la víctima, al no haber sido dirigida por un Juez de acuerdo a las reglas y principios del juicio oral no tiene eficacia probatoria y, por ello, la nueva regulación autoriza a repetir la declaración. En cambio, una segunda interpretación señala que la primera declaración sí tiene eficacia probatoria - pues basta que la misma haya sido correctamente ejecutada y ha sido respetuosa del principio de contradicción, pese a que solamente fue dirigida por el Fiscal-y, en consecuencia, es innecesario repetir la declaración de la víctima —obviamente, sólo en el caso — que es, justamente, al que nos estamos refiriendo- en que el desarrollo de la primera diligencia no amerite una aclaración, complementación o precisión-.

Este es el supuesto - a)(ii) — al que la Corte Suprema presta especial atención en su sentencia de casación, pues resulta claro que ambas interpretaciones antagónicas no pueden convivir a la vez. En esa línea, la Corte Suprema inicia el considerando quinto de la citada casación señalando que desde una lectura gramatical podría asumirse que estamos en presencia de una antinomia. Sobre este primer punto, compartimos el criterio de la Corte Suprema al calificar la contrariedad entre estas dos interpretaciones como una antinomia siempre que se tenga en claro que se está haciendo un uso laxo - genérico- de tal noción, esto es, que se está entendiendo por antinomia cualquier incompatibilidad entre dos normas cualquiera.

Este último apunte es oportuno pues, como señala Pierluigi Chiassoni ${ }^{14}$, caben hasta tres conceptos de antinomia: (a) cualquier incom-

14. Pierluigi Chiassoni, «Antinomias», en Interpretación y razonamiento jurídico, ed. por Santiago Ortega Gomero (Lima: ARA Editores, 2010), 270. 
patibilidad entre dos normas que se asume son simultáneamente vigentes, al menos prima facie, para un mismo ordenamiento jurídico - se trata de un concepto eminentemente genérico que no hace referencia a sus modos de resolución-; (b) cualquier incompatibilidad entre dos normas que no pueda ser eliminada por medio de interpretación; y (c) cualquier incompatibilidad entre dos normas que no pueda ser eliminada por medio de interpretación ni pueda ser superada aplicando un criterio de resolución preconstituido.

En ese sentido, cabe puntualizar que los criterios de resolución de antinomias trabajados ampliamente- en la metodología del Derecho -tanto los formales: el criterio jerárquico, el criterio de competencia, el criterio cronológico; como los materiales: el criterio de especialidad, el criterio de excepcionalidad y el criterio axiológico - aluden a este último tipo de antinomias —las "verdaderas antinomias" - ${ }^{15}$.

Bajo la coherencia de este razonamiento, resulta claro que la noción de antinomia a que alude la Corte Suprema en su sentencia de casación es la primera - concepto genérico de antinomia-, pues esta solo existe desde una interpretación literal de las normas en juego; más desde una lectura que atienda a los fines -teleológica- de estas, aquella se disuelve. No nos hallamos, pues, ni ante la segunda ni tercera noción de antinomia antes expuesta pues ambas exigen como condición negativa el que la incompatibilidad no pueda ser resuelta vía interpretación.

Aclarado este punto - relativo al tipo de antinomia al que alude la Sala Penal Permanente-, corresponde volver a centrarnos en el caso a)(ii).
Como señalamos, la quaestio a dilucidar aquí reside en si, en tales casos, el hecho de que no haya intervenido un Juez ocasiona que dicha diligencia carezca de eficacia probatoria y haga necesaria - pese a la revictimización que ello siempre implica - una nueva declaración de la víctima bajo la dirección de un Juez; o si únicamente para estos casos — realizados bajo el imperio de la anterior regulación-y no así para los nuevos $-c)^{16}$ - resulta suficiente la dirección del Fiscal $y$, por ende, resulta innecesario revictimizar a la presunta víctima mediante una nueva declaración - siempre y cuando la declaración se haya ejecutado correctamente y no haya irrespetado el principio de contradicción-.

Y la solución de la Corte Suprema es categórica: en los casos de estructura a)(ii). no cabe repetir la diligencia. El argumento central para dotar de eficacia probatoria a la primera entrevista pese a que no intervino un Juez- es que mientras ella haya sido ejecutada correctamente $y$ haya respetado el principio de contradicción, resulta innecesario volver a revictimizar a la presunta víctima - ponderación del principio de interdicción de la doble victimización, así como del principio general del interés superior del niño- ${ }^{17}$. En ese sentido, el argumento de la preclusión procesal -la declaración, vía prueba preconstituida, es un acto procesal agotado que creó efectos inalterables- es secundario pues depende de la anterior dilucidación.

Sin embargo, nos preguntamos: si basta para los casos a)(ii) que la diligencia haya sido ejecutada correctamente, respetado el principio de contradicción para que contenga eficacia probatoria, ¿por qué con relación a los casos dados con la nueva regulación se supedita tal eficacia a la dirección de un Juez? Y la respuesta es que

15. Ibíd., 308.

16. En donde, no cabe duda, debe intervenir un Juez.

17. En ese sentido, la Corte Suprema señala: "Empero, lo esencial y determinante desde la perspectiva jurídica es que la entrevista única se realice bajo los requisitos antes indicados, de ser así, tendrá eficacia probatoria y, por ende, podrá ser valorada por el Juez conforme a las reglas de la sana crítica". - Por "requisitos antes indicados" la Corte Suprema alude a la corrección de la ejecución de la diligencia —a cargo de un experto y bajo protocolos consolidados-y el respeto del principio de contradicción-. 
la diferencia entre los casos a)(ii) y c) no reside únicamente que en la primera no participa un Juez y en la segunda sí, sino que en los primeros la diligencia ya fue efectuada y en la segunda nos estamos refiriendo a diligencias que van a realizarse. La diferencia es fundamental pues supone que en los casos a)(ii) ya ha existido una revictimización de la presunta víctima — no se parte de cero-; en cambio en los casos c) aún no se dado esa previa victimización.

En ese sentido, el problema se simplifica —erróneamente- si es que se lo presenta como una controversia ceñida en discernir entre menores - prueba preconstituida - o mayores - prueba anticipada - cánones de garantía, pues no se trata únicamente de eso. Se trata, también, en relación a estos casos a)(ii), de decidir entre menores -otorgarle eficacia probatoria y evitar una nueva declaración de la víctima- o mayores - negarle eficacia probatoria y aceptar una nueva declaración de la víctima-grados de revictimización de las presuntas víctimas.

En cambio, en lo relativo a los casos c) la cuestión es más sencilla: en tanto todavía no se ha recibido la declaración de las víctimas — se parte de cero- el exigir que ésta se lleve a cabo con la participación del Juez no "carga" con el peso una previa victimización. Presentado así el panorama, la solución de la Corte Suprema nos parece convincente: el principio del interés superior del niño y el principio de interdicción de la doble victimización se verían intolerablemente conculcados si es que se permite una nueva declaración de las presuntas víctimas - ya victimizadas mediante una previa declaraciónbajo el único sustento de que la mediación de un Juez otorgaría mayores niveles de garantía a la nueva diligencia - que trae consigue, a su vez, una nueva revictimización de la víctima-. Es decir, aceptar dos revictimizaciones para mejorar la realización de una diligencia - ejecutada correctamente y respetuosa del principio de contradicción - no constituye un buen saldo, es injusto para con las presuntas víctimas.

Sin embargo, la casación de la Corte Suprema no sólo se refiere a estos casos. También alude a diligencias llevadas a cabo bajo al anterior como prueba preconstituida —esto es, sólo dirigidas por el Fiscal- pero en donde o bien no se siguieron los protocolos, o bien no se respetó el principio de contradicción; a saber, los casos que hemos identificado como b). En estos casos, la Corte Suprema sí admite una repetición de la diligencia — vía prueba anticipada—, pese a que ello implicaría una segunda revictimización de la víctima. Y ello es correcto, pues a diferencia de los casos anteriores a)(ii), aquí la primera diligencia no ha respetado ningún mínimo a fin de otorgarle eficacia probatoria. En otras palabras, tolerar dos revictimizaciones para rehacer una primera diligencia complemente inútil constituye una solución armoniosa entre el principio que prohíbe una innecesaria revictimización y los fines de averiguación de la verdad que persigue el proceso.

Otro aporte aclaratorio, de la casación de la Corte Suprema, alude a los casos llevados a cabo bajo la anterior regulación - dirigidos únicamente por el Fiscal-, correctamente ejecutados y respetuosos del principio de contradicción -a)-, en donde, a diferencia de a)(ii), la declaración de la presunta víctima tuvo algún defecto interno relevante que hace necesario una aclaración, complementación o precisión -a)(i)—. En estos supuestos, la Corte Suprema señala que cabe repetir la declaración -ipese a la revictimización que ello siempre produce en la presunta víctima! - a fin de que se realice la aclaración, complementación o precisión correspondiente.

Repárese en que, a diferencia del supuesto anterior b), aquí la primigenia declaración fue parcialmente útil, esto es, no requiere una repetición in totum, sino sólo la realización de una aclaración, complementación o precisión. Esto no supone que la nueva diligencia no suponga una revictimización —en tanto cada vez que una presunta víctima es llamada a prestar declaración sobre un evento traumático resulta afectada - pero sí que el grado de revictimización aquí - -a)(i) — sea menor en comparación con el caso anterior - b) - en donde esta debe volver a realizar una declaración íntegra sobre lo que le sucedió. Mas también debe advertirse que, en contraste con el caso anterior b), 
en donde la justificación de la repetición de la declaración es patente dada la total inutilidad de la primera diligencia, aquí - a)(i) — la justificación no resulta tan evidente, pues podría argüirse que el principio de averiguación de la verdad -al no resultar tan afectado en estos casos - no ameritaría una nueva declaración de la víctima - con el daño que ella siempre implica-.

Esclarecidos del modo anterior los matices del presente grupo de casos - a)(i)—, mi postura se ubica del lado del criterio de la Corte Suprema. En efecto, si bien es cierto que en estos casos el valor de la averiguación de la verdad no se ve gravemente afectado - puesto que la diligencia es parcialmente útil- como en b), también lo es que, en contraste con b), aquí el grado de revictimización es menor - puesto que la nueva diligencia sólo se circunscribirá a aclarar, complementar o precisar algún punto de la anterior declaración-.

Dicho de otro modo: tolerar dos revictimizaciones para rehacer una primera diligencia parcialmente útil constituye una solución armoniosa entre el principio que prohíbe una innecesaria revictimización y los fines de averiguación de la verdad que persigue el proceso, cuando el grado de revictimización de la segunda declaración es menor - en tanto se ciñe a aclarar, complementar o precisar algún punto-.

En vista a ello resulta fundamental que se valore correctamente:

a) Si en realidad es necesario aclarar, complementar o precisar la primera declaración, pues si no es así en vez de encontrarnos ante este caso - a)(i) - nos hallaremos ante el caso a)(ii) en donde, como vimos, resulta prohibido realizar de nuevo la diligencia; $y$,

b) Que el Juez de investigación preparatoria al llevar a cabo la segunda diligencia la ciña a aclarar, complementar o precisar algún punto de la primera, en tanto que si la transforma en una nueva versión - totalde la primera declaración se rompería la relación de proporción antes mencionada: ante una leve afectación del principio de averiguación de la verdad se ampararía - abusivamente - una grave revictimización de la presunta víctima - la permisión para permitir una nueva declaración de la víctima está condicionada a que ésta se limite a la aclaración, complementación o precisión de algún punto de la primera-.

Finalmente, todo lo dicho y argumentado en relación al caso a)(i) puede aplicarse mutatis mutandis en lo concerniente al caso c)(i). A saber, en los casos en donde al amparo de la nueva regulación se lleven a cabo vía prueba anticipada su repetición está condicionada a que sea imprescindible una aclaración, complementación o precisión de algún punto de ésta.

\section{Análisis de otros acuerdos plenarios - No 01-2011 y 04-2015-.}

Comparto el criterio vinculante de que no haya conclusión anticipada en este tipo de delitos en los juicios orales. La razón es que el agravio tiene que mensurarse por los psicólogos y el Juez debe fijar una pena proporcional.

El Ministerio Público nos hizo conocer que en el año 2016 ha dictado tres resoluciones de la Fiscalía de la Nación sobre la valoración del daño psíquico, evaluación psicológica forense en caso de mujeres y violencia familiar y una directiva para la administración y uso de la cámara Gesell. En el año 2016 ha enviado a un evento internacional en España sobre el abordaje pericial del abuso sexual infantil, luego replicado en su sede principal el 23 de septiembre de 2016. En el año 2017 ha efectuado en distintas sedes fiscales seis cursos y talleres de valoración del daño psíquico de personas adultas, víctimas de violencia intencional, uno de valoración de daño psíquico y otro taller sobre guías de evaluación psicológica forense. En el año 2018, seis eventos, cinco talleres de valoración del daño y un diplomado de entrevistas únicas. El Ministerio Público tiene en promedio 80 cámaras de las cuales solo funcionan 70. Presupuestariamente no se asigna más recursos para implementar la infraestructura para realizar una pericia que

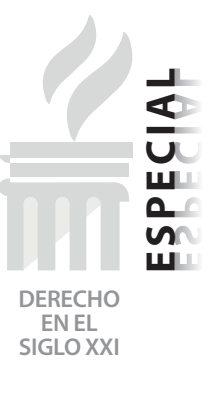


evitaría la revictimización de menores víctimas de abuso sexual.

El Poder Judicial ha recurrido a los acuerdos plenarios. Glosaremos el Acuerdo Plenario $\mathrm{N}^{\circ}$ 01-2011. Destaca el punto 22, referido a la declaración de la víctima en el caso de declaraciones contradictorias que se retractan. Si se verifica la ausencia de incredulidad subjetiva, datos objetivos de mínima corroboración que no sean fantasiosos e incoherentes, deben valorarse debido al tiempo que transcurre cuando se evalúa el testimonio y los sentimientos de frustración y la influencia que genera el ofensor. En el punto 38, subraya la "evitación de la estigmatización de la conducta", señala que la víctima es preguntada numerosas veces sobre el evento, pero que debe ser por única vez e impone las siguientes reglas: reserva de la investigación, preservación de la identidad de la víctima y que la declaración sea por única vez.

El Acuerdo Plenario $N^{\circ}$ 04-2015 trata sobre la valoración de la prueba pericial en delitos de violación sexual. De la cuidadosa lectura y estudio, puede notarse que el concepto de prueba tiene contenido racional: así en el punto 6 nos declara que una pericia es un medio de prueba indirecto, porque proporciona conocimientos científicos para valorar hechos controvertidos. En el punto 11 nos describe el contenido de una pericia oficial y admite plausible que una pericia de parte sea más fiable en razón a la suficiencia de sus conocimientos del perito. En el punto 15, resalta el criterio de la sana crítica y de valoración racional. En el punto 22 indica los criterios de valoración de la prueba pericial, que como en el contradictorio del juicio oral, debe seguir un protocolo y contener los hechos probados en correspondencia con el dictamen, los métodos e instrumentos empleados y su explicación. Si fuera científica - propuesto para la cámara Geselldebe contener los estándares propuestos por la comunidad científica. Resalta en el punto 27 que los peritos deben ser dos y si es uno es excepcional y se debe perennizar. Se adosan en los puntos 28 y 30 criterios de credibilidad del testimonio, en grados mayores y menores si los relatos son fidedignos, así como aspec- tos cognitivos del relato y los componentes emocionales.

Como se puede apreciar, estos acuerdos contienen una serie de directrices procesales que crean un rasgo de cientificidad a la pericia, no son contradictorias, sino que con coherencia deben de aspirar a ser una prueba científica. Considero prudente indicar la conclusión del tópico del perito oficial, dos sistemas de distintas decisiones en la que concluye: "la confianza" del Juez no se refiere a una emoción o virtud, sino, que se trata de una genuina actitud cognoscitiva del perito. "El primer presupuesto del dictamen son las cualidades personales y su competencia profesional como presupuesto de un buen dictamen".

En nuestro medio prima por sobre toda la investigación el dictamen oficial; sin embargo, desconocemos la forma y el mecanismo para formar parte del Instituto de Medicina Legal que recluta a los peritos en base a concursos focalizados al número de exigencias. Debería convocarse por concurso de méritos que incluya remuneraciones atractivas a fin de atraer a los mejores profesionales y crear un instituto de capacitación y de publicaciones de casos que les permita tener conocimientos afirmados a usarse en la exposición y defensa tribunalicia.

La obtención de la información sobre los acontecimientos investigados mediante los testimonios de los testigos es una de las tareas más complicadas a que nos podemos enfrentar. En pocas ocasiones vamos a encontrarnos con testigos ideales, de memoria prodigiosa y capaces de describir minuciosamente todos y cada uno de los detalles relevantes para la investigación. En la mayoría de los casos los testigos no recuerdan bien, cometen errores, olvidan describir lo más importante o no están dispuestos a colaborar tanto como a los investigadores les gustaría. Así pues, un elemento esencial en la investigación criminal es cómo se recupera la información.

Hay algunas formas operativas en el funcionamiento de la Cámara Gesell que refiero con el propósito de mejorarlas y que alcancen el estándar de prueba científica. 
En cuanto a las funciones de la psicología forense relacionadas con el Derecho Penal, podemos empezar por distinguir, por una parte, las relacionadas con la justicia de menores. Aquí los psicólogos forenses se encargarían de la elaboración de informes técnicos sobre la situación psicológica y social del menor que ha delinquido, así como de las posibilidades y vías de reeducación, medidas cautelares, etc.

En el ámbito del Derecho Penal, la psicología forense desarrolla importantes funciones en relación con víctimas y testigos. Cabe señalar la doble condición de la persona que sufre el accidente o acto delictivo y, en multitud de casos, aunque no en todos, ha sido testigo también del suceso.

En cuanto a las víctimas, el trabajo forense suele estar relacionado con la valoración del estado psicológico de la víctima previo al suceso objeto del proceso judicial y, muy importante, con la valoración de las secuelas psicológicas que el accidente o delito ha producido en la víctima.

Como vemos, la obtención y evaluación del testimonio es una más dentro de la variada gama de funciones que aborda la psicología forense. Sin embargo, hay distintas causas que justifican la atención que se le dedica dentro del marco de la psicología forense y los esfuerzos por ampliar los conocimientos dentro de este ámbito. En primer lugar, el estudio y evaluación del testimonio son importantes por las devastadoras consecuencias que tienen para las personas los errores judiciales que se derivan de errores en el testimonio. Pensemos en las personas que han sido acusadas y condenadas por delitos que no cometieron.

En cuanto a los actores, las comisarías, colegios, club de madres o grupos de reivindicación de mujeres que reciben la denuncia se arrogan un trato a su buen entender que en la mayoría de los casos incluye actos de conciliación y requerimiento con el agresor. Solo en casos flagrantes de muerte, peligro o lesión grave la Policía inmediatamente conduce a Medicina Legal, que es un órgano de línea del Ministerio Público. Esta entidad agrupa a médicos legistas, psicólogos, peritos biólogos, criminólogos, tanatólogos y sociólogos forenses. En lo que concierne a psicólogos, en 35 distritos fiscales existen alrededor de 450 psicólogos, de los cuales el número menor de 3 corresponde a Selva Central y el mayor con 28 psicólogos a Lima Norte $^{18}$. La información no precisa si tienen especialidades.

Este dato es trascendente por cuanto los profesionales de carrera, ahora muy relevantes, tienen estudios y habilidades concretas y un gran impacto en conceptos relevantes como verosimilitud y fiabilidad, porque a pesar de usar los mismos tests y baterías como Machover o "la manzana y la familia", la lectura y aplicación que otorga un psicólogo conductista - que indica la afectación psicológica - es distinta a la que otorga un psicólogo legista — cuantifica el grado o nivel leve o permanente-.

Ciertamente, hay conciencia de los profesionales involucrados en este cambio evolutivo porque la gran mayoría siguen maestrías para mejorar las habilidades y adquirir una especialidad que redundará en un mejor servicio; sin embargo, el ente rector —el Ministerio Público- no proyecta políticas de mediano y largo plazo orientadas a mejorar el juicio de autoridad, actualmente la diferencia entre un "perito oficial" con el "perito de parte" se sustenta en su suficiencia: es una persona que debe tener una práctica constante en la materia de su pericia, tener publicaciones y un "récord de práctica judicial" —cuantificar en qué casos han sido determinantes o haber aportado notoriamente en la resolución de un conflicto-. Una de las condiciones es que el examen de su pericia debe tener fiabilidad, basado en la explicación del método que debe ser medible por cualquier auditor. Cada conclusión debe tener un respaldo y debe ser expuesta a un auditorio 
respondiendo y derrotando las contradicciones que se discutan en el juicio. Ciertamente, una pericia en concreto, la cámara Gesell tiene un protocolo normado por un reglamento, conocido como Guía de Procedimientos de Medicina Legal, dos leyes ordinarias y la casuística del acervo cotidiano los cuales no optimizan su eficacia que hemos glosado.

Nuestra crítica es que el número de psicólogos es insuficiente y la ausencia de especialidad que debe promover el Estado es trascendente por el aporte de fiabilidad, verosimilitud o como prueba indirecta o directa, pues, como veremos tenemos deficiencias en la calidad y condición del perito en el Perú. El perito oficial es privilegiado porque el Juez subjetivamente le concede en la valoración un "peso mayor" contra la pericia de parte, que en muchas ocasiones resultan "pericia de pericia" partiendo del dictamen del perito oficial, aunque se desconozcan las calificaciones profesionales, el grado de capacidad o el récord de asertividad del dictamen en condenas y absoluciones. En la literatura del asunto, a nivel de legislaciones de Latinoamérica, Estados Unidos y España, la tendencia es darle la misma condición de estudio al perito oficial y al de parte, y debe primar la suficiencia del dictamen en base al prestigio del perito.

La estructura de la cámara Gesell como pericia es la que más aportes holísticos ha tenido por diversos profesionales. Es un curso central de maestrías de psicología criminal, sociología criminal, estadística y el derecho probatorio y en sentido es casi uniforme que se trata de una habitación acondicionada para observar personas. Tiene dos ambientes separados por un vidrio, sólo se observa de un lado. Uno de ellos está dotado de mecanismo de grabación y audio y el otro para la observación. Para someter a la pericia a niños el ambiente puede contener juegos manuales, muñecos o pinturas. Está incardinado en el Derecho de Familia el uso desde su adopción de la casuística norteamericana, observar a niños - menores de 16 años - sin que sean perturbados. En nuestro medio, según información oficial de Medicina Legal, a nivel nacional han edificado 80 Cáma- ras Gesell y solo funcionan 70, este margen es por la escasa inversión del Estado, a pesar de la recurrencia delictiva. Por gestión de ASPEM, en el distrito del Agustino desde febrero 2013 pusieron en funcionamiento en la sede de Medicina Legal dos ambientes contiguos, uno para la entrevista del psicólogo y otro para que los interesados evalúen y escuchen el testimonio, a ello lo llamó "Sala de Entrevista Única". Este documento, en numerosos atestados y carpetas fiscales van juntos a la entrevista de cámara Gesell, Además, en algunos casos transcripciones literales son acopiados como medios de prueba que sustentan los cargos penales. Este documento, en mi opinión, es una muestra de sobre criminalizar a la víctima, es un problema que afecta su utilidad cuando estos documentos son contradictorios. Esta entrevista única, en esencia busca recibir una declaración impoluta de la víctima que debe ser analizado por otro psicólogo, Fiscal, imputado y abogados, que permita reunir elementos de cargos o de exclusión de cargos; sin embargo, la finalidad de este testimonio prestado a un profesional es reunir visos de fiabilidad o verosimilitud, que lo aporta en la conclusión de la pericia, en tanto ello, lo que se obtiene mediante esta entrevista única - se repite el evento ofensor incluso con relatos distintos-, expuestos a la libre valoración con solo el relato y con este documento se dictan sentencias que tienen penas indeterminadas.

He referido que la cámara Gesell es una pericia en base a un testimonio de una víctima y es de permanente estudio, pues, mayoritariamente para un testimonio - medio de prueba-, requiere una persona - fuente de prueba-. Contiene el concepto estos elementos: es un relato directo - percibido por la persona mediante sus sentidos - o de referencia de hechos precedentes, concurrentes o sobrevinientes que les consta por razones circunstanciales, de función o en proceso de investigación-que la persona aporta con la obligación de expresar la verdad, bajo juramento, excluyendo la mentira y la fabulación.

En el contradictorio se cuestiona la fuente credibilidad, adicción al alcohol, miopía, posi- 
ción condiciones físicas o edad del emisor-y también el testimonio - el relato, su coherencia, las contradicciones de la misma fuente en la entrevista, declaración policial y en el juicio que afirman o desvirtúan la participación del agresor-. Es un problema de orden material cuando en un hecho existen varias versiones de testigos directos debido a muchas razones que la psicología criminal se ha encargado de responder razonablemente.

Los medios de prueba tienen un propósito: acreditan o desacreditan el enunciado fáctico de la acusación o defensa. Aplicando la epistemología en cada pericia y respetando su estructura debe emplearse el método científico que concluya en la fiabilidad del resultado. En este punto, tiene relevancia la pertinencia que se prueba los hechos graficados y limitados en la acusación.

El principio de contradicción es la garantía procesal por excelencia, porque es a través del mismo que el defensor tiene la posibilidad de refutar la veracidad de la prueba del Ministerio Público, sometiendo a un riguroso contrainterrogatorio al órgano de prueba de que se trate: ofendido, testigo, perito, policía de investigación. Esto se traduce en el principio del que habla Popper: falsacionismo — racionalismo crítico-.

Popper sostiene que una teoría que no es refutable por ningún suceso concebible no es científica y que la irrefutabilidad no es una virtud de una teoría, sino un vicio. En este sentido, la "teoría" del Ministerio Público — su postura: Juan mató a Pedro con ventaja - en un procedimiento mixto es irrefutable, porque la prueba es conformada únicamente por el Ministerio Público: él solo, en la etapa de investigación actuando como autoridad, de tal forma que llega ante el Juez con prueba preestablecida, sin que esta se refute durante la instrucción, porque si un testigo que declaró en etapa de investigación es llevado ante el Juez, se desarrolla una ampliación de declaración, en la que el ratifica su declaración primigenia. Además, si la prueba, que consta en documentos, cumple con las formalidades - nombre y firma del agente del Ministerio Público y oficial secretario, sellos, rúbricas, folio, presencia del defen- sor, lectura de derechos a imputados, etc.tiene valor probatorio pleno y contra eso no hay nada que hacer.

Es notable que la persona fuente de prueba presente falsas memorias; la psicología en base a diversos estudios en personas de distinta edad, condiciones normales, de violencia y de naturaleza delictiva, indica que recordamos eventos que no sucedieron, aportamos información al relato diferente a la realidad. Manzanero continua que la memoria no es como una cámara fotográfica que perenniza una escena no es estática, siempre evoluciona, por eso es que en un proceso judicial, en la entrevista, la versión contiene relatos aislados de lo percibido, luego ya con noticia de la relación entre imputado y hecho usando conectores se van afirmando hechos que se infieren. Este estudioso de la facultad de Psicología de la Universidad Complutense de Madrid afirma "sin dudas" que el testimonio es una interpretación en base a experiencias previas.

En los delitos de naturaleza sexual, la cámara Gesell es importante para la obligación de contrastar individual y conjuntamente con otros medios probatorios, porque este testimonio recibido por un profesional o profesionales en condiciones singulares de privacidad y comodidad, en un lenguaje apropiado y procesado, busca su eficacia a partir de la credibilidad del testigo o si lo que exprese sea fiable.

\section{EXACTITUD DEL TESTIMONIO}

La memoria humana no funciona como una cámara de vídeo, sino construyendo a partir de la información percibida y la información almacenada en la memoria de largo plazo una representación de los sucesos que el testigo ha experimentado. Esta representación construida, esta huella de memoria, irá alterándose en función de distintos factores durante un periodo de retención más o menos largo, y cuando el testigo intente recuperar la información que se le solicita, reconstruirá lo sucedido a partir de la información disponible, y, de nuevo, de información relacionada que está en su memoria de largo plazo para construir una des-

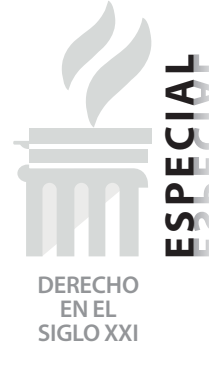


cripción que se producirá habitualmente mediante el lenguaje.

La exactitud absoluta sobre lo que ha sucedido en un evento complejo es una entelequia. Para acercarse a la misma, deberíamos tener un registro sensorial completo -imagen, sonido, olfato, gusto y tacto- desde todas las perspectivas posibles. Algo inimaginable, como podemos comprender inmediatamente. Los testigos y quienes les interrogan solo pueden aspirar a un cierto grado de exactitud relativa, es decir, de correspondencia entre lo que el testigo nos relata y lo que sucedió en realidad.

Los testigos cometen dos tipos de errores: los de omisión, cuando no incluyen en su relato aspectos relevantes del suceso por olvido - de momento solo nos ocuparemos del testigo honesto-; y los de comisión, cuando distorsionan de manera relevante determinados elementos o incluyen otros que no estaban presentes en la situación vivida.

El nivel de exactitud de un testimonio podemos imaginarlo como un cociente entre la información exacta incluida en el relato y la información total que este nos proporciona. Un testimonio puede ser muy breve, y por este motivo a lo mejor no muy útil, pero al no contener información inexacta tendrá un nivel de exactitud elevado. Otro, por el contrario, puede ser extraordinariamente prolijo y detallado pero incluir pocas cosas exactas, con lo cual su nivel de exactitud será muy bajo y, probablemente, será de menos utilidad que el primero. Obviamente, el desiderátum es siempre obtener un testimonio completo, detallado y además exacto.

En lo atinente a la memoria infantil resulta difícil desvirtuar la subjetividad de un operador prejuiciado que concede, desde un inicio, veracidad al relato. En otros sistemas de justicia, como el norteamericano por ejemplo, a estos elementos probados, aislados e incontrovertibles, se les denomina evidencias; en nuestro medio, el acopio de declaraciones testimoniales se somete al contradictorio y se discuten en la etapa intermedia y se analizan en el debate recibiéndose de manera principal esta versión, distinta por el transcurso del tiempo.
Existen otras circunstancias que ponen en cuestión el valor probatorio, en concreto la fiabilidad del testimonio, cuando se trata de hechos colectivos, presenciado por una pluralidad de testigos, pues siendo interpretaciones personales se enriquecen, se complementan. Aún más, estos testimonios se perjudican cuando el relato se complementa con la imaginación de la memoria selectiva: resaltan en ellas, por citar la ropa del agresor, rasgos físicos, detalles de desplazamientos y empleo de extremidades, nutridas por la información de acceso o consignadas en la investigación, en la misma unidad de relato si se le preguntara como andaba vestido el emisor $\mathrm{u}$ otro detalle trascedente no se encuentra focalizado. Se resalta la memoria falsa, que debe ser excluida inmediatamente si el relato de la persona contiene inferencias y es esquemática.

Las fuentes más comunes de error se deben a problemas perceptivos, la interpretación de los hechos, la inferencia de información no procesada, el paso del tiempo y/o la incorporación a los recuerdos de información falsa post suceso. Cada vez que un testigo relata un suceso, piensa en lo que ocurrió y contesta a preguntas sobre las que no tiene una respuesta clara basada en sus propios recuerdos, su memoria sufre transformaciones que aceleran su deterioro más allá de lo que el propio paso del tiempo provocaría. Así pues, por efecto de diferentes factores, la reconstrucción de los recuerdos puede provocar dos tipos diferentes de errores de memoria: errores de omisión y errores de comisión. Los errores de omisión se dan cuando faltan detalles importantes en lo que cuentan los testigos de un hecho. La ausencia de determinados detalles puede deberse a la falta de un lenguaje adecuado para describirlos o incluso al pudor de los testigos para contar determinadas cosas. No esperamos que una víctima de una violación cuente con todo lujo de detalles qué ha ocurrido, pues inevitablemente habrá detalles que omitirá. Los errores de comisión son aquellos en los que los testigos introducen información falsa, deliberadamente - mentira-o debido al efecto de información post suceso, a fallos en la distinción entre realidad y fantasía o a inferencias erróneas. 
En los testimonios recibidos en cámara Gesell se analizan de forma convergente: la exactitud de la memoria, según Mazzoni, la fiabilidad de un testimonio depende de la interacción de la memoria que se obtiene del hecho sucedido, presentándose una relación única, y en el caso del abuso sexual infantil "se agrega una carga psíquica y la debilidad de las influencias externas", por ello en la memoria del menor, puede presentarse la falsa memoria —Jean Piaget refirió que cuando tenía dos años era secuestrado, y este testimonio fue reafirmado por la enfermera, quien 13 años después confesó que nunca se había producido. Este psicólogo, mucho tiempo después, afirmó que debió haber "oído el relato y proyecto el pasado en una memoria visual". Mentir hasta los tres años tiene una causa fisiológica, el lóbulo prefrontal inferior izquierdo no se encuentra desarrollado y este es un lugar donde se almacena la memoria-.

En la misma línea nuevamente Manzanero afirma que la memoria tiene fases: la sensación, que es el significado que uno le otorga; la percepción, que se hace con los sentidos; y el recuerdo, que es la forma de interpretar el evento. Hay algunos puntos que hacemos referencia, en el reiterado concepto que en este medio probatorio, importante y en construcción se sobre criminaliza a la víctima; así son trascendentes la codificación a corto y largo plazo, en la primera la memoria almacena no todo sino lo impactante, en la segunda, se almacena como un episodio y se contextualiza. Por ello, el aforismo de que "el tiempo que pasa es la verdad que huye" plantea que estos testimonios tienen que ser inmediatos, tienen coherencia porque permiten ser verosímiles por la fiabilidad del relato, y siendo únicos no va a requerir la repetición narrativa.

Concurre también que la memoria del menor es veloz y presenta problemas en la comunicación por la formación del lenguaje y el significado que le puede dar a actos enunciados con las mismas palabras. Así, en el catálogo penal, era interesante la distinción etaria de uno a tres años, rangos de siete a ocho y entre doce a catorce años. Actualmente, por cuestiones de zozobra social porque la ley no disuade y estos delitos se cometen con aberraciones complejas, no existe este rango y la punibilidad es de cadena perpetua, con aspiraciones de pena de muerte.

Repercuten en el testimonio los sistemas a los que hemos adosado las declaraciones, por citar las manifestaciones policiales, con la estructura de un sistema inquisitivo el atestado policial, contienen peguntas sugestivas y el resultado o conclusión siempre será de responsabilidad. En la misma línea judicialmente el Juez pregunta y dicta el relato del interrogado y en el juicio inicia y controla el testimonio en aplicación del principio Juez y parte.

En general, el énfasis durante la investigación criminal suele ponerse evidentemente en las víctimas, pero también se recurre casi siempre a los testimonios de los testigos ajenos para corroborar lo manifestado por las víctimas y para conseguir más datos cuando la información aportada por aquéllas parece no ser suficiente. Es imprescindible recurrir a testigos ajenos que puedan ayudar a completar el puzle de lo que en realidad ocurrió si la víctima perdió el conocimiento o tiene un episodio de amnesia asociado al incidente; si se sospecha que no es del todo honesta o bienintencionada - por existir una animadversión especial hacia el denunciado y aparecer grandes contradicciones entre las manifestaciones de unos y otros-, o si están influyendo sobre ella las otras variables ya comentadas - como corta o avanzada edad o discapacidad-.

Estimo con convicción que estos factores determinaron que el testimonio para ser fiable en afectaciones de menores por delitos sexuales debe ser recibido por especialistas cognitivos. Es actuado por un Fiscal y es valorado por un Juez, debe ser impoluto, formal y garantista, como corresponde a un Estado democrático de Derecho. Se confeccione en base a un protocolo y en ninguna situación ni circunstancia debe sobre criminalizar a la víctima.

Daré razones de observación práctica del contenido de las pericias, con la intencionalidad que se mejoren. Sabemos que las pericias de cámara Gesell, -en adelante solo la pericia-, tiene tres etapas reguladas en un protocolo: la primera se conoce como rapport, es la que

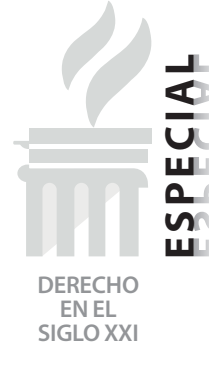


proporciona los datos de víctima de la lectura rápida o de los pocos videos y del documento escrito, estos datos los toma el psicólogo en la misma entrevista. Estimo que lo debe efectuar la asistente social que debe contrastar datos del domicilio, hogar, dependencia económica, pertenencia a hogares disfuncionales, relaciones parentales con el agresor, condiciones de abandono, situaciones concurrentes de alcoholismo, drogadicción y prostitución, datos que deben verificarse en la entrevista previa.

Un tema delicado es que el psicólogo haga la pericia con el sesgo cognitivo de culpabilidad o inocencia. Se plantea el caso de no hacerle conocer al perito el resultado de las otras pericias como el resultado del reconocimiento médico legal, por la tendencia a ser coherente con la teoría del caso propuesto. El perito oficial, que tiene ventajas, no tiene la presión de ser suficiente ni explicito. En la fase de la entrevista, no se respeta el relato espontáneo y de preguntas cerradas para identificar los actos lesivos ni la identificación de los agresores. La conclusión, fase que el Juez evalúa, no es suficiente porque se limita a expresiones conclusivas, no consta el debate porque necesariamente tienen que ser dos peritos. No se perenniza si es un solo - lo ordena la norma- menos se graba la entrevista por razones presupuestarias. Ello incide en la fiabilidad, porque lo que se debate ante el Juez es ese examen practicado por única vez en la que el perito se ratifica y explica o puede debatir con suficiencia. Casi todas se hacen en una sesión y presentan dificultades para ejercer el derecho de defensa, no se ha previsto literalmente que a esta pericia pueda concurrir un psicólogo de parte cuyas conclusiones puedan debatirse en las conclusiones de la pericia.

De las averiguaciones que he efectuado en otros sistemas de justicia, como el de España - Edith Diges de la facultad de Psicología de la Universidad Complutense de Madrid-y algunos estados de Norteamérica, en los que tienen importancia los estándares de pruebas científicas, esta pericia en condiciones de no violencia tiene un protocolo de varias sesiones y cada fase se contrasta para tener las condiciones de fiabilidad. La exigencia tiene doble entrada, el documento debidamente sustentado y el currículum de asertividad del perito, publicación de obras, debates y actualidad profesional en el interrogatorio.

La facilidad con la que se produce el efecto de la información post suceso engañosa debería hacer conscientes a las personas que habitualmente interrogan a testigos - policías, jueces y abogados - de lo cuidadosos que tienen que ser para no inducir en la formulación de sus preguntas información, exacta o no, que el testigo puede no haber percibido en su experiencia original del suceso.

En los experimentos de Loftus y sus colaboradores que hemos explicado en el apartado anterior, la información no incluida o contradictoria con lo que el testigo había visto en el episodio original se introducía de manera explícita en cuestionarios que el sujeto debía contestar un tiempo después de presenciar el suceso. Sin embargo, el experimento de Loftus y Palmer -1974- nos demuestra la sutilidad con que puede condicionarse la respuesta del testigo.

En esta investigación se presentaba también a todos los sujetos una secuencia de vídeo en la que se veía la colisión de dos automóviles. Un tiempo después, los sujetos respondían a un cuestionario sobre el suceso donde se incluyó una pregunta crítica en la que se manipuló el verbo con el que se formulaba la pregunta. A una parte de los sujetos, se le preguntaba: " $i a$ qué velocidad iban los coches cuando se estrellaron?"; a otros: "¿a qué velocidad iban los coches cuando colisionaron?"; "¿a qué velocidad iban los coches cuando chocaron?"; "¿a qué velocidad iban los coches cuando toparon?"; " ¿a qué velocidad iban los coches cuando contactaron?". El experimento se llevó a cabo con hablantes de lengua inglesa, por lo que los verbos utilizados fueron en esta lengua, pero la idea fue manipular mediante el uso del verbo la violencia del choque y, por consiguiente, la velocidad a la que iban los coches. La tabla 2 resume el promedio de velocidad que dio cada uno de los grupos de testigos interrogados utilizando cada uno de los verbos. 
Tabla 2. Resultados de los experimentos de Loftus y Palmer —1974—.

¿A qué velocidad iban los coches cuando...?

\begin{tabular}{l|l|l|l|l}
\hline Se estrellaron & Colisionaron & Chocaron & Toparon & Contactaron \\
\hline $65,6 \mathrm{~km} / \mathrm{h}$ & $63,2 \mathrm{~km} / \mathrm{h}$ & $61,3 \mathrm{~km} / \mathrm{h}$ & $54,7 \mathrm{~km} / \mathrm{h}$ & $51,1 \mathrm{~km} / \mathrm{h}$ \\
\hline
\end{tabular}

Puede que nos parezca poca la diferencia entre $51 \mathrm{~km} / \mathrm{h}$ y $65 \mathrm{~km} / \mathrm{h}$. Sin embargo, a efectos legales, el testigo fácilmente puede estar informando de una velocidad legal o de una ilegal, con las consecuencias que esto comportaría.

Los policías y jueces se hallan en muchos casos presionados para obtener información que resuelva lo antes posible los casos. Esta presión procede, en primer lugar, de su propio celo profesional y, por otro lado, de la propia sociedad que exige la resolución rápida y efectiva de las investigaciones y los procesos judiciales. Esta presión lleva en muchos casos a que los interrogatorios se conduzcan de manera poco cuidadosa, utilizando procedimientos y preguntas que trasladan la presión al testigo y le inducen a proporcionar información inexacta e inconsistente con lo que realmente ha visto y más acorde con las propias expectativas de quien conduce el interrogatorio.

\section{IMPORTANCIA DE LOS ESTÁNDARES DE PRUEBA}

Si bien el objetivo institucional de la prueba en el procedimiento judicial es la averiguación de la verdad, ello no quiere decir que llegaremos a certezas absolutas ${ }^{19}$ acerca de lo ocurrido, sino solamente a que existe un determinado grado de probabilidad que la hipótesis sobre los hechos sea verdadera ${ }^{20}$. Los estándares de prueba nos sirven, precisamente, para determinar cuál es el grado de probabilidad de una hipótesis para darla por probada. Sin la ayuda de tales estándares caeríamos en una gran inseguridad jurídica, pues no sabríamos cuando una hipótesis sobre los hechos está probada o no.

La importancia de los estándares radica también en que muchas reglas del proceso como por ejemplo la carga de la prueba o principio pro reo- no pueden aplicarse si es que no se conoce el estándar de prueba respectivo. Por ejemplo, el principio in dubio pro reo indica que si no hay prueba suficiente debe absolverse al acusado, empero el conocimiento de cuándo hay prueba suficiente lo brinda el estándar de prueba correspondiente. Esto es, sin la determinación previa de estándares, tales reglas serían inaplicables o, bien se aplicarían arbitrariamente.

\section{CONCLUSIONES}

El medio de prueba denominado cámara Gesell debe ser pericia científica en la que participan más de dos profesiones, el de asistencia social encargado del reporte, y el examen a cargo de dos psicólogos cognitivos que realizan la entrevista y elaboran las conclusiones. Necesariamente fiable.

Puede realizarse fuera del proceso pero con participación de un Juez de turno, - de instrucción o de investigación preparatoria- quien debe observar el protocolo de ejecución en un ambiente adecuado en la que se permita el derecho de defensa. No puede sustituirse por otro medio probatorio.

19. Ello no ocurre en ningún ámbito de conocimiento.

20. El razonamiento probatorio es probabilístico. 
Es un medio de prueba indirecta, facilita al Juez un testimonio de un menor de edad o adolescente afectado de abuso sexual y señala el daño psicológico.

Debe practicarse de manera inmediata, inde- pendiente para evitar el sesgo cognitivo. Los peritos deben estar calificados.

Debe practicarse por una sola vez, solo de esta forma se evitará la revictimización hasta por 15 veces.

Autores varios. Interpretación y razonamiento jurídico, ed. por Santiago Ortega Gomero (Lima: ARA Editores, 2010$), 270$. Beatriz Escudero García-Calderón, El consentimiento en Derecho Penal (Valencia: Tirant lo Blanch, 2014).

Carmen Vázquez, De la prueba científica a la prueba pericial (Lima: Marcial Pons, 2015).

Eugenio Garrido y Jaume Masip, «La evaluación del abuso sexual infantil» (ponencia, I Congreso de Psicología Jurídica y Forense en Red, mayo de 2004).

Jorge Frias Caballero, Nuevos temas penales (Venezuela: Editorial LIVROSCA C.A., 1998).

José Ramón Serrano-Piedacasas Fernandez, Conocimiento Científico y Fundamentos del Derecho Penal (Lima: Gráfica Horizonte S.A., 1999).

Marina Gascón Abellán, Cuestiones probatorias (Universidad Externado de Colombia, 2012).

Marcelo Sancinetti, «De la insuficiencia del testimonio único, con especial referencia al abuso sexual», Revista Internacional Derecho Penal Contemporáneo, n. ${ }^{4} 1$ (2012).

Miguel Pizarro Guerrero, Programa de control del crimen: Diagnóstico y propuestas. Serie Ensayos. (Lima: Ediciones IURE, 2015).

Pablo Guerez Tricarico, «Presupuestos de la licitud jurídico-penal del tratamiento médico curativo: el papel del consentimiento del paciente» (tesis doctoral, Universidad Autónoma de Madrid, 2011). 